\title{
Patterns of domestic violence and alcohol consumption among women and the effectiveness of a brief intervention in a household setting: a protocol study
}

Carla Ferreira de Paula Gebara ${ }^{1 *}$, Cleusa Pinheiro Ferri ${ }^{1}$, Lelio Moura Lourenço ${ }^{2}$, Marcel de Toledo Vieira ${ }^{3}$, Fernanda Monteiro de Castro Bhona ${ }^{2}$ and Ana Regina Noto ${ }^{1}$

\begin{abstract}
Background: Domestic violence and harmful alcohol consumption are considered major public health problems worldwide. These phenomena often co-occur, and they share several risk factors. Nevertheless, few in-depth studies have supported integrated interventions for both phenomena, in particular among Latin American women. This project will study the consumption of alcoholic beverages among women and its relationship with patterns of domestic violence; furthermore, it will assess the effect of a brief intervention (BI) aimed at modifying these behaviors using a community household sample.

Methods/design: This project is divided into two studies. Study 1 will employ a cross-sectional observational design and will be conducted using a household sample of adult women (approximate sample size $=1600$ ) to assess harmful alcohol consumption and domestic violence patterns. Study 2, will be a randomized clinical trial based on specific cases from Study 1, assessing the effect of a brief intervention on women who exhibit harmful levels of alcohol consumption (AUDIT $\geq 8$ ). Approximately 73 women will be assigned to one of two groups, either a treated group (TG) or a control group (CG). A sociodemographic questionnaire, a questionnaire concerning general health and substance use, and four other standardized instruments (i.e., the Alcohol Use Disorder Identification Test [AUDIT; used to investigate problems related to alcohol consumption], the Center for Epidemiologic Studies Depression Scale [CES-D; used to measure depressive symptoms], and the Revised Conflict Tactics Scales and Parent-child Conflict Tactics Scales [CTS2 and CTSPC; used to obtain information on violence among couples and between parents and children, respectively]) will be used to collect data.

Discussion: The study protocol will employ a household survey of a representative sample from a neighborhood in a middle income country, where well-conducted household surveys remain rare. The present work represents a step toward a better understanding of violence in women's lives and its interaction with alcohol consumption and expands the discussion on the potential strategies for public health actions seeking to prevent both domestic violence and harmful alcohol consumption.
\end{abstract}

Trial registration: Brazilian Clinical Trials Registry: RBR-7rjt4t. Registered 17 October 2013.

Keywords: Domestic violence, Alcohol, Brief intervention, Women

\footnotetext{
* Correspondence: carla_gebara@yahoo.com.br

'Department of Psychobiology, Research Center on Health and Substance Use (NEPSIS), Universidade Federal de São Paulo (UNIFESP), Botucatu St., 862-First floor, São Paulo, SP 04023-062, Brazil

Full list of author information is available at the end of the article
} 


\section{Background}

Domestic violence and harmful alcohol consumption are two key public health problems worldwide [1]. In addition to their high prevalence, both phenomena result in considerable biological, psychological, and sociological repercussions for individuals and the general population $[1,2]$. These phenomena often co-occur and share a complex set of psychosocial risk factors. However, in-depth studies aimed at supporting interventions to address both phenomena in an integrated manner remain scarce, especially among specific groups such as Latin American women.

\section{Alcohol consumption among women}

Although alcoholic beverage consumption remains higher among men, women have significantly increased their consumption because of society's changing gender roles [3]. According to the Global Burden of Diseases, Injuries, and Risk Factors Study in 2010 [4], alcohol consumption is the third leading risk factor for illnesses and disabilities worldwide; furthermore, the World Health Organization (WHO) considered it to be the primary risk factor for "disabilityadjusted life years" (DALYs) in Tropical Latin America, which encompasses certain Latin America countries including Brazil. Depending on consumption patterns, alcohol can affect individual's health due to accidents, dependence, liver cirrhosis, cancer, and injury. Alcohol consumption can also affect the health of other people in community and family settings, specifically due to drinking and driving situations, work absenteeism, drinking during pregnancy, and cases of violence and neglect in the parent-child relationship [2].

Previous Brazilian surveys suggest that approximately $75 \%$ of the population has consumed alcohol at least once in their lifetime [5], and nearly $25 \%$ of respondents reported at least one type of drinking-related problem. Furthermore, $3 \%$ meet the criteria for alcohol abuse, and $9 \%$ are alcohol dependent [6]. These rates varied based on gender, age, marital status, educational level, income, and country region with approximately $4 \%$ of women abusing alcohol or being alcohol dependent [7].

It has been suggested [3] that biological factors such as lower body weight and lower fat-to-muscle ratios contribute to faster and more intense effects of alcohol among women. Compared with men, harmful alcohol consumption among women has a disproportionate effect on their lives and health, including undesired consequences regarding reproductive function and pregnancy as well as the faster development of physical, cognitive, social, and psychiatric problems $[3,8,9]$.

\section{Domestic violence}

Like alcohol consumption, violence (specifically, domestic violence) has been identified as a priority for WHO actions. Violence is a major public health problem worldwide because it has serious implications for health (in both the short and long term) as well as the psychological and social development of individuals, families, and communities [10, 11].

Domestic violence (or family violence) can be understood as "every act or omission committed by some family member in a position of power, regardless of where it occurs, which harms the well-being, physical or psychological integrity, or freedom and right to full development of another family member" [12]. Violent acts can be classified based on their type, including acts of physical, psychological, and sexual violence; alternatively, they can be expressed as forms of neglect or abandonment [11]. In the family setting, violence can occur within interpersonal relationships, including those with children, adolescents, men, women, and the elderly [13-15]. Despite the increased emphasis placed on victimized women within partnerships [11], researchers recognize that women can also be the aggressor in the marital relationship [13, 16, 17] and with regard to their children [18, 19].

Some studies suggest that domestic violence is highly prevalent and has a complex network of associations. Some of the factors associated with domestic violence include younger age, lower education level, a history of physical violence in the family, childhood sexual abuse, depression, poor socioeconomic conditions, and problems related to alcohol consumption among one or both members of the couple [20-23]. The consequences of domestic violence can be identified at different levels of life, leading to physical and psychosocial impairments. [24, 25]. Therefore, it becomes important to treat family violence as a complex phenomenon, one that tends not to be restricted to a single member of the family [22].

\section{Domestic violence and alcohol}

Although many studies relate alcohol consumption to violent behavior, it is not possible to establish a simple and unidirectional association because of the complexity of this relationship [1, 26-29]. A population-based study in Brazil found that the aggressor was under the influence of alcohol at the time of the event in over half of the identified cases of domestic violence [14]. The literature includes several other studies that suggest an association between alcohol consumption and violent behavior among intimate partners [1, 30-35].

Although some studies have suggested that alcohol consumption is more associated with the severity of violence acts than to increases in its occurrence [31, 36], others have suggested that it should be related to both [35] and that the association between alcohol and violence becomes more powerful with increased consumption [26, 29]. To better understand how alcohol consumption might be related to a greater severity of domestic violence, it is important to consider not only the pharmacological effects of alcohol but 
also the environmental and sociocultural factors that influence patterns of alcohol consumption and violent behaviors [31].

Alcohol is a risk factor for the occurrence of violent acts because it has direct effects on physical and cognitive performances, contributing to violence by reducing self-control as well as reducing judgment and the ability to recognize signs of danger. Moreover, individual and cultural beliefs that alcohol causes aggression can lead to its intake in preparation or as an excuse/justification for violent acts [1]. It is also possible that harmful alcohol consumption is a coping strategy adopted by victims to address the stress caused by violent situations $[1,37]$.

Although strong associations seem exist between domestic violence and alcohol abuse among women, few studies have been conducted regarding the peculiarities of this association, especially in developing countries such as Brazil. Given this association, the WHO recommends measures to reduce the availability and the harmful consumption of alcohol as important strategies to prevent violence. There is some evidence on the success of brief interventions (BIs) in reducing various forms of violence, including domestic violence [1].

\section{Early detection and intervention for harmful alcohol consumption}

The early detection of alcohol abuse is essential in preventing the future consequences of this consumption, because it enables the early application of interventions [38-40]. Given that many users do not recognize they have a problem in the early stages, interventions that allow problems to be recognized and behaviors to be changed become necessary.

BIs that are targeted on primary or secondary prevention strategies among alcohol consumers focus on changing an individual's behaviors through limitedtime therapies that can be performed by professionals with different backgrounds $[39,41]$. Despite the variations in the forms of BIs application (e.g., in person, by phone, or online), the theoretical framework of motivational interviewing [42] and the principles of cognitivebehavioral therapy are usually employed.

Because BIs are an effective, low-cost strategy for treating problems related to alcohol and drugs, it is also a useful tool for prevention and a way to facilitate the referral of severe cases (e.g., those with alcohol dependence) to specialized treatments [38, 41, 43]. Previous studies have suggested that BIs work for different types of patients and that their effectiveness can be equal to or even better than those of interventions that require more time to complete [44]. Although BIs have been shown to be effective when performed by skilled professionals or researchers [41, 45], in clinical settings or in the context of routine health services, there is a lack of studies regarding the use of these techniques in community household settings. Such an approach should reach populations who do not have access to or choose not seek out the healthcare system; furthermore, it represents an alternative to the difficulties of implementing BIs in the healthcare services.

A comprehensive review of the BIs applied in primary care concluded that this approach decreases alcohol use among men; however, these findings were not extended to women. Therefore, additional research regarding the most effective components of such interventions is needed among this specific population [43]. Moreover, another literature review [46] identified promising results for women, despite the significant heterogeneity observed among the analyzed clinical trials. Because the evidence for the effectiveness of BIs remains contradictory among women [43, 46, 47], a well-conducted study that establishes the effectiveness of BIs is necessary for this population group, especially within developing countries. The assessment of BIs in community household settings is especially relevant in Brazil because this country has a strong strategy for primary health services that is focused on providing home care to families.

The current protocol is designed to study the association between alcohol consumption and patterns of domestic violence among women. Study 1 aims to (1) estimate the rates of harmful alcohol consumption and domestic violence (within the couple and that directed toward children) among adult women; (2) assess the association between the sociodemographic and mental health factors with regard to the harmful consumption of alcoholic beverages; and (3) assess the association between the sociodemographic and physical and mental health factors as well as between alcohol consumption and the occurrence of domestic violence (within the couple and that directed toward children).

Nested within Study 1, Study 2 aims to evaluate the effectiveness of BIs on women with harmful alcohol consumption living in a community household setting in reducing their alcohol consumption and patterns of domestic violence (within couples and toward children).

\section{Methods}

\section{Study design}

Study 1 will employ a cross-sectional observational design to investigate the patterns of alcohol consumption and domestic violence using a household survey of women. Study 2 will be a randomized clinical trial (RCT) nested within Study 1 (i.e., the women identified as having harmful alcohol consumption in Study 1 will be invited to take part in the RCT.

\section{Setting}

The current study will be conducted in Juiz de Fora, Minas Gerais, southeastern Brazil; this city has approximately half 
a million inhabitants. The study will randomly select women living in two neighborhoods with different average monthly incomes per capita according to the Instituto Brasileiro de Geografia e Estatística (Brazilian Institute of Geography and Statistics; IBGE) census conducted in 2000. This categorization will be used to investigate two populations with different income profiles.

\section{Sampling}

To calculate the sample size needed for this cross-sectional study, the data from a previous study (which estimated the prevalence of harmful alcohol consumption among women in Juiz de Fora as approximately $9.1 \%$ ) will be considered [48]. In addition, this study considered a maximum measurement error of $3 \%, 95 \%$ confidence intervals, a finite population correction based on the number of women residing in the randomly selected neighborhoods (consistent with the 2000 IBGE census), an effect of the sampling design equal to 2 , and a $25 \%$ refusal to participate rate. Thus, the initial sample size was estimated as 824 respondents (412 in each neighborhood).

To calculate the clinical trial sample size, the following considerations will be made: (i) a significance level of $5 \%$; (ii) a statistical power of $80 \%$ (to compare proportions of the two independent groups); (iii) a non-interview rate of $15 \%$ due to refusal to participate or failure to locate the informant; (iv) the effect of the BI after 3 months (i.e., an expected reduction of at least $20 \%$ in the number of women with harmful alcohol consumption; and (v) an effect of the sampling design equal to 2 . Thus, the calculated sample size for each group (i.e., the treated group [TG] and control group [CG]) will be 73 women.

To make the second study possible, considering the prevalence of women with risky alcohol consumption in the two neighborhoods surveyed around the estimated above (ie, $9.1 \%$ ), there will be necessary an increase in the sample size for Study 1, which now has approximately 1600, with 800 in each of the neighborhoods.

To recruit the women who belong to the target population, a two-stage cluster sampling method will be adopted. The streets belonging to each neighborhood will be considered as primary sampling units (PSUs), and households will be considered as secondary sampling units (SSUs). To select PSUs, a simple random sampling method without replacement will be adopted, whereas the SSUs will be selected using systematic sampling. In each selected household, the field researchers will invites all women who met the inclusion criteria to participate in the study.

\section{Inclusion criteria}

Female residents in the two neighborhoods who are aged 18-60 years, literate, and without obvious cognitive impairments will comprise the target sample. Domestic violence behaviors will be investigated among women who have children of aged up to 18 , husbands or partners, or both residing in the same household.

\section{Measurements}

\section{Participant sociodemographic characteristics}

Information concerning ethnicity, age, education level, religion, occupation, marital status, and number of children will be obtained. Among women who are married or cohabitating, information regarding the duration of their relationship will be obtained along with the sociodemographic characteristics of their partners (e.g., age, education level, and occupation).

\section{Alcohol consumption}

Alcohol consumption will be assessed using the Alcohol Use Disorders Identification Test (AUDIT), a screening tool developed by the WHO [49] that consists of 10 questions: 3 concerning consumption amount and frequency, 3 regarding dependence symptoms, and 4 concerning personal and social problems related to alcohol abuse. The final score reflects the following alcohol consumption levels or patterns: abstainers/low risk ( $0-7$ points), hazardous use (8-15 points), harmful use (16-19 points), and probable dependence (20-40 points). The AUDIT has been previously validated in several countries, including Brazil, and shows good sensitivity $($ mean $=0.90)$ and specificity (mean $=0.80$ ) regarding the detection of harmful alcohol consumption $[49,50]$.

Information concerning the respondents' use of any healthcare service over the previous 3 months, the approach of health professionals regarding respondents' alcohol consumption, respondent participation in any treatment for alcohol consumption, and the respondents' perceptions of their partners' alcohol consumption will also be obtained.

\section{Consumption of other substances}

Information regarding the consumption of tobacco, marijuana, amphetamines, benzodiazepines, antidepressants, and cocaine over the three months preceding the interview will be obtained.

\section{Health}

A structured 15-question instrument concerning the respondents' general health and the presence of specific diseases such as hypertension, diabetes, and heart problems will be administered.

\section{Depression}

The population-based screening scale for depression from the Center for Epidemiologic Studies (i.e., the CES-D) will be used. This screening instrument seeks to identify depressive symptoms within adult population-based studies [51]. Consisting of 20 items, its total score ranges from 0 
to 60 points, with the higher scores indicating a greater amount of depressive symptoms. The cutoff of 16 points is often used to classify individuals as having possible depression. The CES-D has been previously validated for use in Brazil and shows satisfactory levels of reliability $[52,53]$.

\section{Domestic violence}

The Revised Conflict Tactics Scales (CTS2) will be employed to collect information on violence between intimate partners, whereas the Parent-child Conflict Tactics Scales (CTSPC) will be used to assess domestic violence by women against their children.

The CTS2 was designed to assess violence within couples, and it provides data on the respondent and her partner. This survey consists of 78 items, and each item is displayed in a set of two questions. The first question of each set refers to a possible behavior of the respondent, whereas the second refers to the same action but experienced by the partner. This instrument consists of 5 subscales that address the occurrence of negotiation, psychological aggression, physical violence, consequences of violence affecting the health of the respondent and her partner (i.e., injuries), and sexual coercion within the relationship. The CTS2 shows an internal consistency between $0.65-0.86$ and an intra-observer reliability (kappa) above 0.75 when evaluated in Brazilian samples to assess its conceptual equivalence, semantic equivalence, and psychometric properties [54-56].

The CTSPC was designed based on the refinement of the previous instrument, and it addresses the parentchild relationship. This instrument is composed of questions regarding the occurrence of certain behaviors directed at children. Its 22 items are divided into three levels: nonviolent discipline (e.g., explaining errors and applying punishment), psychological aggression (e.g., swearing, screaming, threatening to kick the child out, or hitting), and physical assault (e.g., face slapping, throwing the child on the floor, or threatening with a knife); the latter was subdivided into corporal punishment, physical abuse, and severe physical abuse. The CTSPC had previously been cross-culturally adapted for use in Brazil; furthermore, prior work found that its internal consistency ranged from $0.49-0.68$, and estimates of its intra-observer reliability (kappa) were above $0.75[57,58]$.

According to Straus [59] (the author of the CTS2 and CTSPC), these instruments investigate the occurrence of behaviors that, unlike emotions, attitudes, and beliefs, are less susceptible to distortions with regard to the interpretation of facts. Importantly, the methodological choice for these assessments reflects an understanding of domestic violence as a complex phenomenon that tends not to remain restricted to only one member of the family [58]. Furthermore, research indicates that violent acts are typically reciprocal, i.e., the respondent might be both the aggressor and the victim [60].

The information regarding alcohol consumption provided by the respondent and her partner during episodes of violence will also be incorporated by adapting the violence scales. After each CTS2 and CTSPC item, the interviewer will ask whether one of the involved individuals was under the influence of alcohol when the event occurred.

The CTS2 and CTSPC will be self-applied, whereas all of the other instruments will be administered to participants during interviews. Except for the CES-D, which refers to the events of the previous week, all of the instruments will be adapted to consider a time period of three months.

\section{Procedure}

\section{Study 1: Household survey}

A researcher will approach the participants at their homes; all of the instruments will be administered there. The interviews will take approximately $30 \mathrm{~min}$ to complete and will be held in a place as private as possible to allow the interviewees to freely answer questions and increase the credibility of their answers.

The researchers will be properly trained women who will initially approach the participants to invite them to volunteer for the survey, delivering a document that describes the study and its objectives. The training of the team will consist of attending lectures on domestic violence, alcohol consumption, BIs, the project details, a clarification of the study's procedures, and an explanation of the questionnaires. Furthermore, the importance of research ethics will be emphasized. The researchers will gain familiarity with the instruments by administering them to a colleague. Training will be provided on the application of a BI via videos and role-playing techniques.

To locate the women living in the randomly selected households, at least three visits will be made to each household. When a resident is not found at her supposed address, the researchers will seek information from the neighbors to identify the existence of any women who meet the eligibility criteria for the study and the best days and times to approach them.

\section{Study 2: Random clinical trial}

The data collection for Study 2 will be conducted concomitantly using the women detected in Study 1 . Women with AUDIT scores equal to or above 8 will be considered as hazardous alcohol users and randomly allocated into one of two groups: the TG or the CG. The TG will receive a single BI after the instrument is administered, whereas the CG will not receive BI until after the end of the study. 
The participants will be allocated using a list of random numbers. Three months after the BI, all instruments except for the sociodemographic questionnaire will be re-administered to both groups. Because of ethical reasons, a BI session will also be offered to the CG after the second evaluation, at the end of the study. Independent interviewers will perform the baseline and the follow-up interview.

\section{The intervention}

The BI will be performed at the participants' households in accordance with the model proposed by Miller and Sanchez [61], the principles of which are summarized by the acronym "FRAMES". This acronym stands for "Feedback" (provide information regarding the score obtained on the screening instrument), "Responsibility" (the patient must take responsibility for changing their behavior), "Advice" (guidance on issues related to the use of substances and coping strategies), "Menu of options" (a list of options or alternative behaviors to substance use), "Empathy" (putting one's self in another's shoes based on one's own assumptions to try to understand their behavior), and "Self-efficacy" (patients' belief in their ability to change).

The timing of the BI will be controlled, ranging from 15 to $40 \mathrm{~min}$. After administering the procedure, the researcher will record the approach used and the participant's behavior during the intervention.

\section{Ethics}

This study has been approved by Ethics Committee of the Federal University of São Paulo (Universidade Federal de São Paulo; UNIFESP- registration number 0699/10). The study has also been registered in the Brazilian Clinical Trials Registry (ReBEC; registration number: RBR-7rjt4t).

All participants will receive information about the study, and their participation will be voluntary. Each participant will be required to sign an informed consent document. At the end of the interviews, all participants will receive an informational leaflet regarding the use of alcoholic beverages, as well as a guide concerning health services and psychosocial assistance in cases of violence and alcohol dependence. After the follow-up assessment is performed three months after the screening, the $\mathrm{BI}$ will be applied to participants in the CG. Women who score in the range of "probable alcohol dependence" (i.e., 20 points or more on the AUDIT) will be instructed to seek specialized treatment, regardless of the group to which they are allocated.

\section{Statistical analyses}

Given the characteristics of the adopted sampling design, the data will be processed and analyzed using the statistical software STATA version 11.
Initially, exploratory bivariate analyses will be conducted to assess the associations between the variables of interest and the possible risk factors. Chi-square tests will be used to test the association between categorical variables, whereas Student's $t$-test will be used to compare the means of continuous variables.

A logistic regression model will be used to examine the patterns of alcohol consumption with the response variable and the sociodemographic and health characteristics as explanatory variables. A separate logistic regression model will be used with the type of violence as dependent variable and the sociodemographic and health characteristics, and alcohol consumption patterns as explanatory variables.

The TG and CG will be compared using t-tests and generalized linear models with repeated-measures.

\section{Discussion}

Both alcohol consumption among women and violence within the family are relevant public health problems which are mediated by cultural and contextual factors [20]. Despite the purported associations between these phenomena, studies providing information on their characteristics among women using community samples are scarce in Brazil [19, 21, 62].

This study includes a household survey with representative samples of two neighborhoods with different socioeconomic profiles in Brazil, a developing country where well-conducted household surveys remain rare. Although the cross-sectional design does not allow for the inference of causality, this approach will broaden the discussion on the relationship between alcohol consumption and violence, considering the individual and environmental aspects involved in these phenomena.

This study not only proposes to present a better understanding of violence in the lives of women (regardless of its association with alcohol consumption) but also expand the discussion regarding the possible public healthcare strategies and actions needed to prevent domestic violence and harmful alcohol consumption [1]. With regard to alcohol, the use of a BI in a community household setting represents a new method of prevention that could have indirect effects on domesticviolence-related problems.

We believe that this protocol has the potential to support supplementary studies aiming to promote knowledge regarding two of the most important public health problems from different perspectives: harmful alcohol consumption and domestic violence. Furthermore, we believe that the results of this study might influence both clinical practice and prevention efforts in the context of public health.

\section{Abbreviations}

AUDIT: Alcohol use disorders identification test; BI: Brief intervention; CES-D: Center for epidemiologic studies depression scale; CTS2: Revised conflict tactics scales; CTSPC: Parent-child conflict tactics scales; 
DALYs: Disability-adjusted life years; IBGE: Brazilian institute of geography and statistics; WHO: World health organization.

\section{Competing interests}

The authors declare that they have no competing interests.

\section{Authors' contributions}

$C G, A N, L L$ and FB participated in the study design and the definition of objectives and goals of the study. MV was responsible for the sample design. CF made the proposal of the statistical analyzes. CG, AN and CF drafted the manuscript and made the final revision of the text. All authors read and approved the final manuscript.

\section{Authors' information}

CG was a PhD student from the Department of Psychobiology of Universidade Federal de São Paulo (UNIFESP). FB is a PhD student from the Department of Psychology of Universidade Federal de Juiz de Fora (UFJF). MV is a professor from the Department of Statistics of UFJF and LL is a professor from the Department of Psychology of UFJF. CF and AN are professors from the Department of Psychobiology of UNIFESP. CG, AN and CF are researchers of Research Center on Health and Substance Use (NEPSIS), FB and LL are researchers of Center for Studies on Violence and Social Anxiety (NEVAS).

\section{Availability of data and materials}

$$
\text { Not applicable. }
$$

\section{Acknowledgments}

This study is developed with the support of the following agencies: the São Paulo Research Foundation (FAPESP; Fundação de Amparo à Pesquisa do Estado de São Paulo; processes no.: 2010/51094-7 and no.: 10/51837-0), the National Council of Technological and Scientific Development (CNPq; Conselho Nacional de Desenvolvimento Cientifico e Tecnológico, process no:: 400675/2010-2) and the Research Incentive Fund Association (AFIP; Associação Fundo de Incentivo à Pesquisa).

\section{Funding}

This study has been funded by the São Paulo Research Foundation (FAPESP; Fundação de Amparo à Pesquisa do Estado de São Paulo; processes no: 2010/51094-7 and no: 2010/51837-0) and the National Council of Technological and Scientific Development (CNPq; Conselho Nacional de Desenvolvimento Cientifico e Tecnológico, process no: 400675/2010-2). The study also has been developed with the support of the Research Incentive Fund Association (AFIP; Associação Fundo de Incentivo à Pesquisa).

\section{Author details}

'Department of Psychobiology, Research Center on Health and Substance Use (NEPSIS), Universidade Federal de São Paulo (UNIFESP), Botucatu St., 862-First floor, São Paulo, SP 04023-062, Brazil. ²Department of Psychology, Center for Studies on Violence and Social Anxiety (NEVAS), Universidade Federal de Juiz de Fora (UFJF), Juiz de Fora, MG, Brazil. ${ }^{3}$ Department of Statistics, Universidade Federal de Juiz de Fora (UFJF), Juiz de Fora, MG, Brazil.

Received: 19 December 2014 Accepted: 17 September 2015 Published online: 24 September 2015

\section{References}

1. World Health Organization. Violence prevention: The evidence. Preventing violence by reducing the availability and harmful use of alcohol. Geneva: World Health Organization; 2009. p. 18.

2. World Health Organization. Global status report on alcohol and health Geneva: World Health Organization; 2011. p. 286.

3. World Health Organization. Gender, health and alcohol use. Geneva: WHO Department of Gender, Women and Health; 2005.

4. Murray CJL, Vos T, Lozano R, Naghavi M, Flaxman AD, Michaud C, et al. Disability-adjusted life years (DALYs) for 291 diseases and injuries in 21 regions, 1990-2010: A systematic analysis for the Global Burden of Disease Study 2010. Lancet. 2012;380(9859):2197-223.
5. Galduroz JC, Carlini EA. Use of alcohol among the inhabitants of the 107 largest cities in Brazil-2001. Braz J Med Biol Res = Revista Bras Pesquisas Med Biol/Soc Bras Biofisica [et al]. 2007;40(3):367-75.

6. Laranjeira R, Pinsky I, Sanches M, Zaleski M, Caetano R. Alcohol use patterns among Brazilian adults. Rev Bras Psiquiatr. 2010;32(3):231-41.

7. Caetano R, Madruga C, Pinsky I, Laranjeira R. Drinking patterns and associated problems in Brazil. Adicciones. 2013;25(4):287-93.

8. Kay A, Taylor TE, Barthwell AG, Wichelecki J, Leopold V. Substance use and women's health. J Addict Dis. 2010;29(2):139-63.

9. Nilsen P. Brief alcohol intervention to prevent drinking during pregnancy: an overview of research findings. Curr Opin Obstet Gynecol. 2009;21(6):496-500.

10. García-Moreno C, Jansen H, Ellsberg M, Heise L, Watts C. WHO multi-country study on women's health and domestic violence against women. Geneva: World Health Organization; 2005.

11. Krug EG, Mercy JA, Dahlberg LL, Zwi AB. The world report on violence and health. Lancet. 2002;360(9339):1083-8.

12. Shrader E, Sagot, M. Domestic violence: women's way out. Pan American Health Organization [PAHO]. Washington, DC. 2000. x, 124 p.

13. Dossi AP, Saliba O, Garbin CA, Garbin AJ. [Epidemiological profile of domestic violence: Complaints of aggression filed in a city in Sao Paulo State, Brazil from 2001 to 2005]. Cadernos Saude Publica. 2008;24(8):1939-52.

14. Fonseca AM, Galduroz JC, Tondowski CS, Noto AR. Alcohol-related domestic violence: A household survey in Brazil. Rev Saude Publica. 2009;43(5):743-9.

15. Rodriguez Franco L, Lopez-Cepero J, Rodriguez Diaz FJ. [Domestic violence: A bibliographic and bibliometric review]. Psicothema. 2009;21(2):248-54.

16. Archer J. Sex differences in physically aggressive acts between heterosexual partners: A meta-analytic review. Aggress Violent Behav. 2002;7(4):313-51.

17. Moore TM, Stuart GL, Meehan JC, Rhatigan DL, Hellmuth JC, Keen SM. Drug abuse and aggression between intimate partners: A meta-analytic review. Clin Psychol Rev. 2008;28(2):247-74.

18. Canha J. The child victim of violence. In: Machado C, Gonçalves RA, editors Orgs.) [Violence and crime victims] (vol.2, 3rd edition,pp 17-37. Portugal: Editora Quarteto; 2008

19. Zaleski M, Pinsky I, Laranjeira R, Ramisetty-Mikler S, Caetano R. Intimate partner violence and contribution of drinking and sociodemographics: The Brazilian National Alcohol Survey. J Interpers Violence. 2010;25(4):648-65.

20. Abramsky T, Watts CH, Garcia-Moreno C, Devries K, Kiss L, Ellsberg M, et al. What factors are associated with recent intimate partner violence? Findings from the WHO multi-country study on women's health and domestic violence. BMC Public Health. 2011;11:109.

21. d'Oliveira AFPL, Schraiber LB, Franca I, Ludermir AB, Portella AP, Diniz CS, et al. Factors associated with intimate partner violence against Brazilian women. Rev Saude Publica. 2009;43(2):299-310.

22. Reichenheim ME, Dias AS, Moraes CL. [The co-occurrence of physical violence against partners and their children in health services]. Rev Saude Publica. 2006;40(4):595-603.

23. Gilchrist G, Hegarty K, Chondros P, Herrman H, Gunn J. The association between intimate partner violence, alcohol, and depression in family practice. BMC Fam Pract. 2010;11:72.

24. Johnson MP: Differentiating among types of domestic violence. Marriage and family: Perspectives and complexities 2009:281-297.

25. Tolan P, Gorman-Smith D, Henry D. Family violence. Annu Rev Psychol. 2006;57:557-83.

26. Babor T, Caetano R, Casswell S, Edwards G, Giesbrecht N, Graham K, et al. Alcohol: No ordinary commodity. Research and public policy. Oxford: Oxford University Press; 2003.

27. Bennett $L$, O'Brien P. Effects of coordinated services for drug-abusing women who are victims of intimate partner violence. Violence Against Women. 2007;13(4):395-411.

28. Laranjeira R, Duailibi SM, Pinsky I. [Alcohol and violence: Psychiatry and public health]. Rev Bras Psiquiatr. 2005;27(3):176-7.

29. Moreira TC, Belmonte EL, Vieira FR, Noto AR, Ferigolo M, Barros HM Community violence and alcohol abuse among adolescents: A sex comparison. J Pediatr (Rio J). 2008;84(3):244-50.

30. Boden JM, Fergusson DM, Horwood LJ. Alcohol misuse and violent behavior: Findings from a 30-year longitudinal study. Drug Alcohol Depend. 2012;122(1-2):135-41.

31. Graham K, Bernards S, Wilsnack SC, Gmel G. Alcohol may not cause partner violence but it seems to make it worse: A cross-national comparison of the relationship between alcohol and severity of partner violence. J Int Violence. 2011;26(8):1503-23. 
32. Kaplan LM, Hill TD, Mann-Deibert GR. Does alcohol consumption exacerbate the mental health consequences of interpersonal violence? Violence Against Women. 2012;18(3):289-308

33. Selic P, Pesjak K, Kersnik J. The prevalence of exposure to domestic violence and the factors associated with co-occurrence of psychological and physical violence exposure: A sample from primary care patients. BMC Public Health. 2011;11:621

34. Tartakovsky E, Mezhibovsky S. Female immigrant victims of domestic violence: A comparison between immigrants from the former Soviet Union in Israel and Israeli-born women. J Fam Violence. 2012;27(6):561-72.

35. Tumwesigye NM, Kyomuhendo GB, Greenfield TK, Wanyenze RK. Problem drinking and physical intimate partner violence against women: Evidence from a national survey in Uganda. BMC Public Health. 2012:12:399.

36. Leonard KE. Alcohol and intimate partner violence: When can we say that heavy drinking is a contributing cause of violence? Addiction. 2005;100(4):422-5.

37. Kaysen D, Dillworth TM, Simpson T, Waldrop A, Larimer ME, Resick PA. Domestic violence and alcohol use: Trauma-related symptoms and motives for drinking. Addict Behav. 2007;32(6):1272-83.

38. Babor TF, Higgins-Biddle JC. Brief interventions for alcohol abuse in primary health care. Ribeirão Preto: PAI-PAD; 2003.

39. Babor TF, McRee BG, Kassebaum PA, Grimaldi PL, Ahmed K, Bray J. Screening, Brief Intervention, and Referral to Treatment (SBIRT): Toward public health approach to the management of substance abuse. Subst Abus. 2007:28(3):7-30.

40. Ronzani TM, Mota DC, Souza IC. Alcohol prevention within primary care in municipalities in the state of Minas Gerais, southeastern Brazil. Rev Saude Publica. 2009;43 Suppl 1:51-61.

41. Nilsen P, Kaner E, Babor TF. Brief intervention, three decades on. Nordic Stud Alcohol Drugs. 2008;25:6.

42. Miller WR, Rollnick S: Motivational interviewing: Preparing people for change. New York: Guilford press; 2002.

43. Kaner EFS, Dickinson HO, Beyer FR, Pienaar E, Campbell F, Schlesinger C, Heather N, Saunders JB, Burnand B, Pienaar ED. Effectiveness of brief alcohol interventions in primary care populations. Cochrane Database of Systematic Reviews 2007(2), DOI: 10.1002/14651858.CD004148.pub3.

44. Formigoni MLOS, Ronzani TM. [Effectiveness and cost-benefit ratio of brief interventions] in: [national antidrug secretariat - senad. (org.) system for the detection of theabuse, use of and addition to psychoactive substances SUPERA]. 2ed. Basília Senad - Governo Federal. 2008:4:58-63.

45. Aasland $O G$, Nygaard P, Nilsen $P$. The long and winding road to widespread implementation of screening and brief intervention for alcohol problems: A historical overview with special attention to the WHO initiatives. Nordic Stud Alcohol Drugs. 2008;25(6):469-76.

46. Gebara CF, Bhona FM, Ronzani TM, Lourenco LM, Noto AR. Brief intervention and decrease of alcohol consumption among women: A systematic review. Substance Abuse Treat Prevent Policy. 2013;8:31.

47. Floyd RL, Weber MK, Denny C, O'Connor MJ. Prevention of fetal alcohol spectrum disorders. Dev Disabil Res Rev. 2009:15(3):193-9.

48. Amato TC, Silveira PS, Oliveira JS, Ronzani TM. Use of alcoholic drinks, religion and other sociodemographic characteristics in primary health care patients - Juiz de Fora, MG, Brazil - 2006. SMAD Revista Eletrônica Saúde Mental Alcool Drogas. 2008;4(2):00.

49. Babor TF, Higgins-Biddle JC, Saunders JB, Monteiro MG: The alcohol-use disorders identification test. Guidelines for use in primary care, Second Edition, Department of Mental Health and SubstanceDependence, World Health Organization; 2001.

50. Lima CT, Freire AC, Silva AP, Teixeira RM, Farrell M, Prince M. Concurrent and construct validity of the audit in an urban Brazilian sample. Alcohol. 2005:40(6):584-9.

51. Radloff LS. The CES-D Scale: A self-report depression scale for research in the general population. Appl Psychol Meas. 1977;1(3):385-401.

52. Fleck MP, Lima AF, Louzada S, Schestasky G, Henriques A, Borges VR, et al. [Association of depressive symptoms and social functioning in primary care service, Brazil]. Rev Saude Publica. 2002;36(4):431-8

53. Silveira DX, Jorge MR. [Psychometric properties of the epidemiologic screening scale for depression (CES-D) in clinical and non-clinical populations of adolescents and young adults]. Psiq Clin. 1998;25:251-61.

54. Moraes $\mathrm{CL}$, Hasselmann MH, Reichenheim ME. [Portuguese-language crosscultural adaptation of the Revised Conflict Tactics Scales (CTS2), an instrument used to identify violence in couples]. Cadernos de Saude Publica. 2002:18(1):163-76.

55. Moraes $\mathrm{CL}$, Reichenheim ME. Cross-cultural measurement equivalence of the Revised Conflict Tactics Scales (CTS2) Portuguese version used to identify violence within couples. Cadernos Saude Publica. 2002;18(3):783-96.

56. Reichenheim ME, Klein R, Moraes CL. Assessing the physical violence component of the revised conflict tactics scales when used in heterosexual couples: An item response theory analysis. Cadernos Saude Publica. 2007;23(1):53-62.

57. Reichenheim ME, Moraes CL. [A Portuguese-language cross-cultural adaptation of the parent-child conflict tactics scales (CTSPC), an instrument used to identify parental violence against children]. Cadernos Saude Publica. 2003:19(6):1701-12.

58. Reichenheim ME, Moraes CL. The psychometric properties of the Portuguese version of the Conflict Tactics Scales: Parent-child version (CTSPC) used to identify child abuse. Cadernos Saude Publica. 2006;22(3):503-15.

59. Straus MA. Blaming the messenger for the bad news about partner violence by women: The methodological, theoretical, and value basis of the purported invalidity of the conflict tactics scales. Behav Sci Law. 2012;30(5):538-56.

60. Whiting JB, Simmons LA, Havens JR, Smith DB, Oka M. Intergenerational transmission of violence: The influence of self-appraisals, mental disorders, and substance abuse. J Fam Violence. 2009:24(8):639-48.

61. Miller WR, Sanchez V. Motivating young adults for treatment and lifestyle change. In: Howard G, editor. Issues in alcohol use and misuse by young adults. Notre Dame IN: University of Notre Dame Press; 1993.

62. Zanoti-Jeronymo DV, Zaleski M, Pinsky I, Caetano R, Figlie NB, Laranjeira R. [Prevalence of physical abuse in childhood and exposure to parental violence in a Brazilian sample]. Cadernos Saude Publica. 2009:25(11):2467-79.

\section{Submit your next manuscript to BioMed Central and take full advantage of:}

- Convenient online submission

- Thorough peer review

- No space constraints or color figure charges

- Immediate publication on acceptance

- Inclusion in PubMed, CAS, Scopus and Google Scholar

- Research which is freely available for redistribution 